\title{
A Numerical Study for the Effects of Sub-channels on Combined Thermal and Hydrodynamic Effectiveness in a Plate Heat Exchanger Designed for Balanced Ventilation
}

\author{
${ }^{1}$ Murat Ünverdi and ${ }^{* 1}$ Hasan Küçük \\ ${ }^{* 1}$ Faculty of Engineering, Department of Mechanical Engineering, Sakarya University, Turkey
}

\begin{abstract}
In this study, the effects of the number of sub-channels on the thermal and hydrodynamic performance of plate heat exchangers (PHEs) designed to be used in balanced ventilation systems have been investigated numerically. In the design of PHEs, Taguchi method was used for 4 different effective factors (average air flow velocity, channel height, number of sub-channels and plate material) in 3 levels. Numerical analyzes of PHE models were performed with a CFD based package program (ANSYS/Fluent). In Taguchi analysis, 2 and 6 sub-channels PHE models obtained close results $(<1 \%)$ in terms of the number of sub-channels according to the selected performance parameter (combined thermal and hydrodynamic effectiveness-CTHE). And thus, the changes in recovered thermal power, pressure drop, flow effectiveness and thermal effectiveness in both PHE models were investigated depending on the average air flow velocity. According to the recovered thermal power and CTHE, it was found that the optimal average air flow velocity for both PHE models was $1.5 \mathrm{~m} / \mathrm{s}$. It has been determined that 2 sub-channels model is more advantageous in terms of thermal and hydrodynamic performance, weight and production cost.
\end{abstract}

Key words: Plate heat exchanger, Taguchi method, heat recovery in balanced ventilation, Computational Fluid Dynamics, combined thermal and hydrodynamic effectiveness

\section{Introduction}

Nowadays, individuals in cities generally spend about $90 \%$ of their lives indoors. A comfortable indoor should be at the appropriate temperature, sufficiently light and enough fresh air. When outdoor conditions differ from indoor conditions, energy is used for lighting and increasing or decreasing the indoor air temperature. Concerns about climate change, depletion of limited natural resources, and environmental pollution are constantly increasing the tendency and attempts to use less energy to provide comfort in buildings. In order to save energy in air conditioning and ventilation systems, heat losses in the building envelope can be reduced by using insulation materials. Heat losses from ventilation can also be reduced by preventing uncontrolled ventilation and minimizing air leakage through the building envelope. Therefore, new buildings are well insulated and their envelopes are airtight [1-4].

The fresh air taken into the building is at outdoor temperature. Consequently, for example, when the outside air is cold, fresh air must be heated in order to keep the indoor comfortable. Previously heated but polluted indoor air should also be thrown out to maintain comfort conditions. For these reasons, in new buildings, mechanical ventilation systems have become necessary both to reduce

*Corresponding author: Address: Faculty of Engineering, Department of Mechanical Engineering Sakarya University, 54187, Sakarya TURKEY. E-mail address: kucuk@ sakarya.edu.tr, Phone: +902642955723 
heat loss and to supply sufficient fresh air. Because the outdoor air cannot enter the indoor uncontrollably from the airtight envelope of these buildings. For these reasons, recovering heat from polluted air that needs to be exhausted is a logical and practical solution $[1,5]$.

The balanced ventilation system is a system that recovers heat from stale air discharged to the outdoor and transfers it to the fresh outdoor air taken into the building. Fresh and stale air flows are balanced, as no further openings are required for ventilation in the building. Therefore, the total amount of air in the building does not change. Heat energy is also transferred from one air stream to another in the heat recovery unit, which is an air to air heat exchanger. Balanced ventilation systems usually consist of two fans and two ducts. In a typical balanced ventilation system, fresh air is supplied to bedrooms and common rooms where people spend the most time, while stale air is discharged from indoors where moisture and pollutants are released, such as kitchens, bathrooms and laundry rooms. As a result, balanced ventilation systems that are designed, installed and operated appropriately meet the ventilation needs of residences without any pressure difference between the indoor and outdoor [5-7].

Heat exchanger used in the heat recovery unit, heat transfer takes place between the stale air discharged from the indoor and the fresh air taken from the outdoor. In this way, the heat energy carried by the ventilation air is continuously recovered and the energy bill for heating/cooling is reduced. By using balanced ventilation system, it is stated that $7 \%$ energy saving can be achieved compared to classical ventilation systems. In a heat exchanger design for a balanced ventilation system, as much heat transfer as possible is desired. There must be a balance between the heat exchanger dimensions (as compact as possible to reduce initial investment cost) and the system's electrical energy consumption. That consumption of the fans in system is directly related to the pressure losses of the air streams in the heat exchanger [8-10].

In this study, the effect of number of sub-channels on the combined thermal and hydrodynamic performance of an air-to-air cross-flow PHE, designed for use in the ventilation system of a small residence and operating under balanced ventilation conditions, has been investigated. CFD and Taguchi method were used in determination of the operating variables and in the dimensional and structural design of the PHE which will operate in the flow range of $50-200 \mathrm{~m}^{3} / \mathrm{h}$. In the Taguchi method, the number of sub-channels, channel height, plate material and average air flow velocity were selected as effective design and operating 3-level parameters. In the Taguchi method, the parameter levels (number of sub-channels: 6, channel height: $3 \mathrm{~mm}$, average air flow velocity: 2 $\mathrm{m} / \mathrm{s}$ and plate material: paper) that will maximize the CTHE of PHE, which is selected as performance parameter, were determined. However, the Taguchi analysis for the highest CTHE showed that the effect of the number of sub-channels on the performance was less than the other design parameters. In other words, the effect of the number of sub-channels is less than $1 \%$ in the comparison between 2 sub-channels PHE and 6 sub-channels PHE models according to the average of S/N ratios. That's why, in this study, other PHE design and operation variables except for the number of sub-channels were kept constant, and the effect of the number of sub-channels on CTHE and other performance parameters was investigated numerically and the results were compared. 


\section{Taguchi Method and Numerical Solution}

\subsection{Taguchi Method}

Using the Taguchi method, it is possible to evaluate the factors affecting performance or outcome with the least number of experiments or numerical analyzes. In the literature, optimization studies are carried out in many different fields with Taguchi method. In the Taguchi method, third-level orthogonal arrays (OAs) such as $\mathrm{L}_{9}, \mathrm{~L}_{18}$ and $\mathrm{L}_{27}$ are commonly used. In the Taguchi experimental design, the results of experiments using these OAs are primarily converted to the Signal/Noise $(\mathrm{S} / \mathrm{N})$ ratio. $\mathrm{S} / \mathrm{N}$ ratios are calculated and analyzed in three different ways: larger-the better, smaller-the-better or nominal-the-best, depending on the desired performance result. In the Taguchi method, the $\mathrm{S} / \mathrm{N}$ ratio is maximized and so the effect of the signal on noise is increased while the variation on the result is reduced $[11,12]$.

In this study, S/N ratios were used as larger-the better criterion for the CTHE. With the formula expressed below, the larger-the better $\mathrm{S} / \mathrm{N}$ ratio can be calculated [13].

$S / N=-10 \log \left(\frac{1}{n} \sum_{i=1}^{n} 1 / y_{i}^{2}\right)$

In the above expression, $\mathrm{y}$ is the observed data and $\mathrm{n}$ is the number of observations. In this study, $\mathrm{L}_{9} \mathrm{OA}$ was used for 4 control factors, each having 3 levels. In the PHE design, the number of subchannels, channel height, average air flow velocity and plate material were chosen as control factors. Table 1 shows the list of 9 different models prepared for PHE design in accordance with the OA L9. According to the larger-the better performance category, Taguchi results has been evaluated with prepared calculation based on Taguchi steps in Microsoft/Excel.

Table 1. 9 different designed numerical PHE models according to Taguchi L 9 orthogonal array

\begin{tabular}{ccccc}
\hline Numerical run number & $\mathrm{N}$ (number) & $\mathrm{H}(\mathrm{mm})$ & $\mathrm{u}(\mathrm{m} / \mathrm{s})$ & $\mathrm{M}$ \\
\hline 1 & 2 & 2 & 2 & Aluminum foil \\
2 & 2 & 3 & 2.5 & Paper \\
3 & 2 & 4 & 3 & ABS Film \\
4 & 6 & 2 & 2.5 & ABS Film \\
5 & 6 & 3 & 3 & Aluminum foil \\
6 & 6 & 4 & 2 & Paper \\
7 & 18 & 2 & 3 & Paper \\
8 & 18 & 3 & 2 & ABS Film \\
9 & 18 & 4 & 2.5 & Aluminum foil \\
\hline
\end{tabular}

Following the Taguchi method, ANOVA analysis is applied to determine the optimum levels of the selected effective parameters. In ANOVA analysis, the effect of each factor on the targeted PHE performance is calculated by converting it to a percentage value. The effect values (\%) of the factors are calculated using the sum of the squares values in the ANOVA table. A larger value for 
any factor indicates that the effect of that factor on the targeted performance parameter is greater than the others $[11,12,14]$. In addition, the optimum value of the performance parameter can be estimated when the optimum levels of the parameters are used by applying the additivity law [15].

\subsection{Numerical Solution}

The plate heat exchangers are compact and in the form of a block of flow channels formed by the addition of separate plates and support elements. Numerical analyzes have been considered in 3dimensional because of a great number of plates in PHEs and the cross-flow of the two air streams. In 3-D numerical analyzes, half of the fresh and stale air channels are modeled to shorten the solution time. In addition, 3-D numerical PHE models are designed to evaluate the inlet-outlet effects of air streams on PHE channels. ABS (Acrylonitrile Butadiene Styrene, $\mathrm{k}=0.15 \mathrm{~W} / \mathrm{mK}$ ), aluminum foil $(\mathrm{k}=202.4 \mathrm{~W} / \mathrm{mK})$ and paper $(\mathrm{k}=0.09 \mathrm{~W} / \mathrm{mK})$ were selected for the heat transfer plate having a thickness of $0.2 \mathrm{~mm}$. While the stale air is assumed to enter the PHE at $298 \mathrm{~K}$ and the fresh air at $283 \mathrm{~K}$ [16], thermo-physical properties of the air are taken from Ref. [17].

The mesh structure independence was carried out with 5 different PHE numerical models at the highest average air flow velocity. In the analyses of PHE numerical models, structural meshes have been preferred to obtain a fine mesh distribution. Besides, the boundary layer mesh structure was used near the surface where heat transfer occurs. The results of the mesh structure independence study performed are given in Table 2 . Schematic representation of boundary conditions and the results of the mesh independence study for 6 sub-channels PHE model has been discussed in detail in Ref. [18].

Table 2. Mesh number independence studies of outlet temperature and pressure drop for 2 sub-channels model

\begin{tabular}{ccccc}
\hline Mesh number & $\begin{array}{c}\text { Fresh air outlet } \\
\text { temperature }(\mathrm{K})\end{array}$ & $\begin{array}{c}\text { Stale air outlet } \\
\text { temperature }(\mathrm{K})\end{array}$ & $\begin{array}{c}\text { Fresh air outlet } \\
\text { pressure }(\mathrm{Pa})\end{array}$ & $\begin{array}{c}\text { Stale air outlet } \\
\text { pressure }(\mathrm{Pa})\end{array}$ \\
\hline 1497898 & 290.08 & 290.92 & 38.11 & 38.11 \\
1800526 & 289.59 & 291.42 & 33.04 & 33.11 \\
2215052 & 289.44 & 291.57 & 31.10 & 32.01 \\
2562572 & 289.29 & 291.71 & 29.85 & 30.52 \\
3117254 & 289.29 & 291.71 & 30.69 & 30.35 \\
\hline
\end{tabular}

In numerical analyzes, Enhanced Wall Treatment was chosen as the wall function on plate surfaces. Standard k- $\varepsilon$ (epsilon) turbulence model was used because of considering the inlet-outlet effects of PHE channels. The default Under-Relaxation factors are pressure: 0.3 , momentum: 0.7 , turbulence kinetic energy: 0.8 and turbulence dissipation rate: $0.8 .10^{-3}$ convergence criteria for the continuity, components of velocity, $\mathrm{k}-\varepsilon$ equations and $10^{-8}$ convergence criteria for the energy equation were used. Navier-Stokes and turbulence model equations were discretized in ANSYS/Fluent and solutions were completed by selecting the SIMPLE (Semi-Implicit Method for Pressure-Linked Equations) algorithm and the second order upwind separation scheme. In the numerical solution, the temperature and velocity profiles at the inlet were assumed to be uniform and the pressure at the outlets constant (pressure outlet $=0$ ) [19-21]. 
According to numerical solutions, the conservation of mass for both air streams and the conservation of energy between the stale and fresh air streams [22]:

$$
\begin{aligned}
& \dot{m}_{\text {inlet }}=\dot{m}_{\text {outlet }} \quad(\mathrm{kg} / \mathrm{s}) \\
& E_{\text {inlet }}=E_{\text {outlet }} \quad(\mathrm{kJ})
\end{aligned}
$$

According to the results of numerical solution, the flow effectiveness which is the flow energy consumed per recovered heat energy, and thermal effectiveness were calculated as follows [23]:

$$
\begin{aligned}
& \varepsilon_{f}=Q_{r h} / P_{\text {fan }} \\
& \varepsilon_{t}=\left(Q_{r h} / Q_{\max }\right) \times 100
\end{aligned}
$$

The recovered thermal power, fan power (flow energy to be consumed to overcome the pressure losses), maximum thermal power and CTHE defined as follows [23, 24]:

$$
\begin{aligned}
& Q_{r h}=\dot{m} c_{p}\left(T_{f a, o}-T_{f a, i}\right) \\
& P_{f a n}=2 \times\left(\frac{\dot{\forall}}{3600} \times \Delta p\right) \\
& Q_{\text {max }}=\dot{m} c_{p}\left(T_{s a, i}-T_{f a, i}\right) \\
& \varepsilon_{C T H E}=\varepsilon_{f} \times \varepsilon_{t}
\end{aligned}
$$

\section{Results and Discussions}

In this study, the effect of the number of sub-channels on the thermal and hydrodynamic performance of a cross-flow PHE (plate dimensions and total volume fixed) designed to be used in heat recovery in balanced ventilation systems has been investigated numerically. Using the Taguchi and CFD approach in PHE design, the required design and operational variable levels for the highest CTHE of the PHE were determined. The effective variable levels obtained with these approaches as the number of sub-channels: 6, channel height: $3 \mathrm{~mm}$, average air flow velocity: 2 $\mathrm{m} / \mathrm{s}$ and plate material: paper [18]. However, according to the average of Taguchi $\mathrm{S} / \mathrm{N}$ ratios, the effect of the number of sub-channels on CTHE is less than 1\%. In numerical analyzes, other PHE design variables except for the number of sub-channels were kept constant, and the effects of the number of sub-channels on CTHE, which is the performance parameter, were investigated. In addition, in order to evaluate the effects of the number of sub-channels, two different PHE ( 2 and 6 sub-channels) designs were compared to the changes in recovered thermal power, pressure drop, flow effectiveness and thermal effectiveness based on the average air flow velocity. 
Figure 1a shows the changes of recovered thermal powers depending on the average air flow velocity. The recovered thermal powers increase with the average air flow velocity as expected. In both PHE models, there was no significant difference in the recovered thermal powers up to $2 \mathrm{~m} / \mathrm{s}$. However, at velocities above $2 \mathrm{~m} / \mathrm{s}$, the increase in recovered thermal power is greater in the 6 subchannels PHE model with the increase of average air flow velocity. The recovered thermal power for 6-channels PHE model is 5\% higher than 2-channels PHE model at the average air flow velocity of $3.5 \mathrm{~m} / \mathrm{s}$.
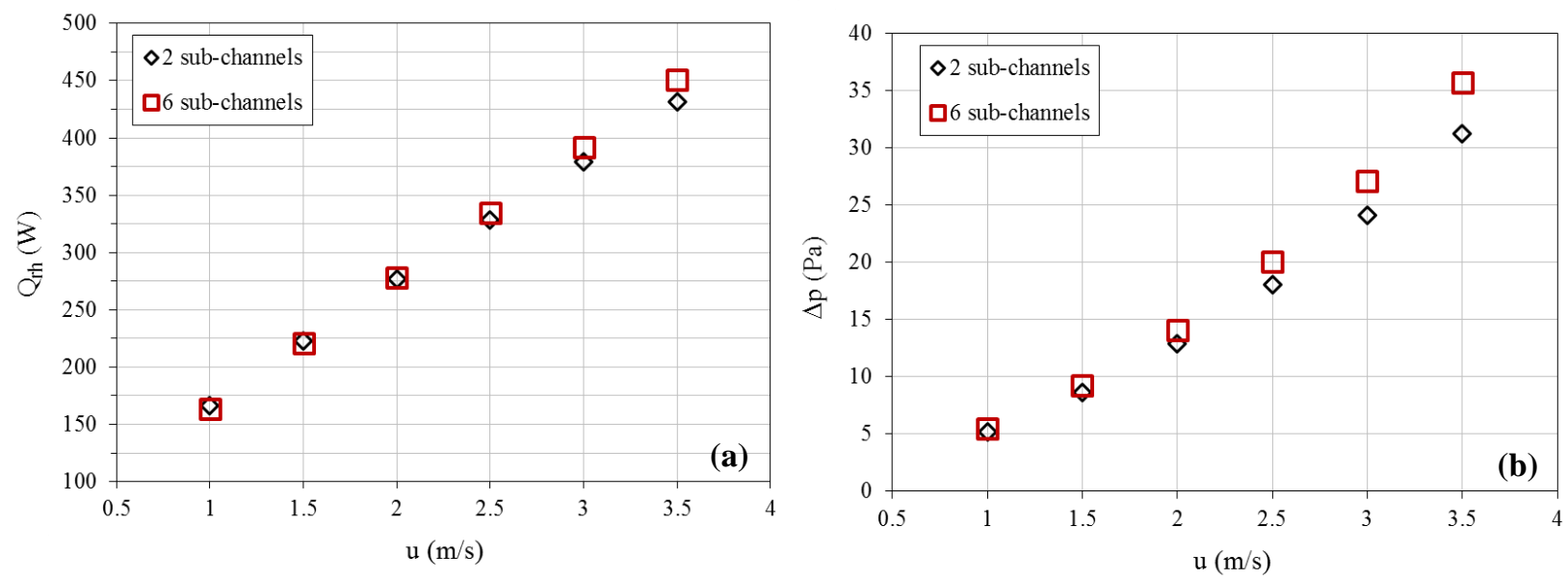

Figure 1. Changes in (a) recovered thermal power and (b) pressure drop depending on average air flow velocity

Figure $1 \mathrm{~b}$ shows the changes in the pressure drops for both PHE models depending on the average air flow velocity. The pressure drops in both PHE models showed a similar trend as in the recovered thermal power. In the 6 sub-channels PHE model, in the investigated air flow velocity range $10 \%$ more pressure drop is obtained than the 2 sub-channels model, while the difference in pressure drops varies between 5\% -15\%. Especially in the 6 sub-channels PHE model above $2 \mathrm{~m} / \mathrm{s}$, there is an average 3\% increase in the recovered thermal power and but $12 \%$ increase in the pressure drop on average. It makes, therefore, the 2 -sub channels PHE model more advantageous.
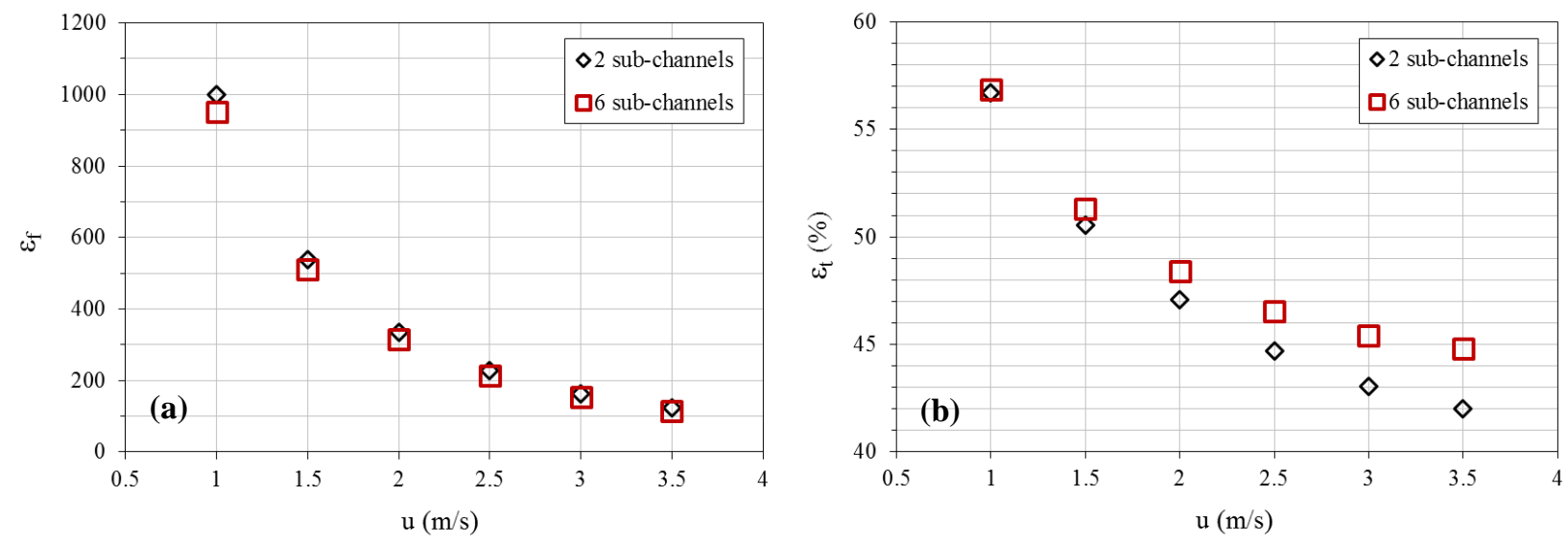

Figure 2. Changes in (a) flow effectiveness and (b) thermal effectiveness depending on average air flow velocity 
In order to more clearly evaluate this situation, in Figure 2a, the change of the flow effectiveness, which is defined as the ratio of fan power consumed per recovered thermal power, to the average air flow velocity has been given. The flow effectiveness of both PHE models decrease with increasing average air flow velocity. In the average air flow velocity range examined, the flow effectiveness of the 2 sub-channels PHE model is on average $6 \%$ higher than the 6 sub-channels PHE model. The 6 sub-channels PHE model, which is more advantageous in terms of recovered thermal power, is disadvantageous in terms of pressure drop and flow effectiveness.

Figure $2 \mathrm{~b}$ shows the changes in the thermal effectiveness of both PHE models depending on the average air flow velocity. The change in thermal effectiveness showed a similar trend to the change in flow effectiveness. Thermal effectiveness changes between $42-57 \%$ in the velocity range 1-3.5 $\mathrm{m} / \mathrm{s}$. However, in terms of thermal effectiveness, the 6 sub-channels PHE model is more advantageous than the 2 sub-channels PHE model.

In the $1-1.5 \mathrm{~m} / \mathrm{s}$ velocity range, the difference between the thermal effectiveness of both PHE models is less than $1 \%$, whereas in the $2-3.5 \mathrm{~m} / \mathrm{s}$ velocity range, the differences between the thermal effectiveness of the above-stated models are 3\%-7\%. The 2 sub-channels PHE model is advantageous in terms of recovered thermal power, pressure drop and flow effectiveness at average air flow velocities of less than $2 \mathrm{~m} / \mathrm{s}$. It is difficult to decide which model is more advantageous above the average air flow velocity of $2 \mathrm{~m} / \mathrm{s}$. Therefore, the CTHE changes depending on the average air flow velocity have been given in Figure 3.
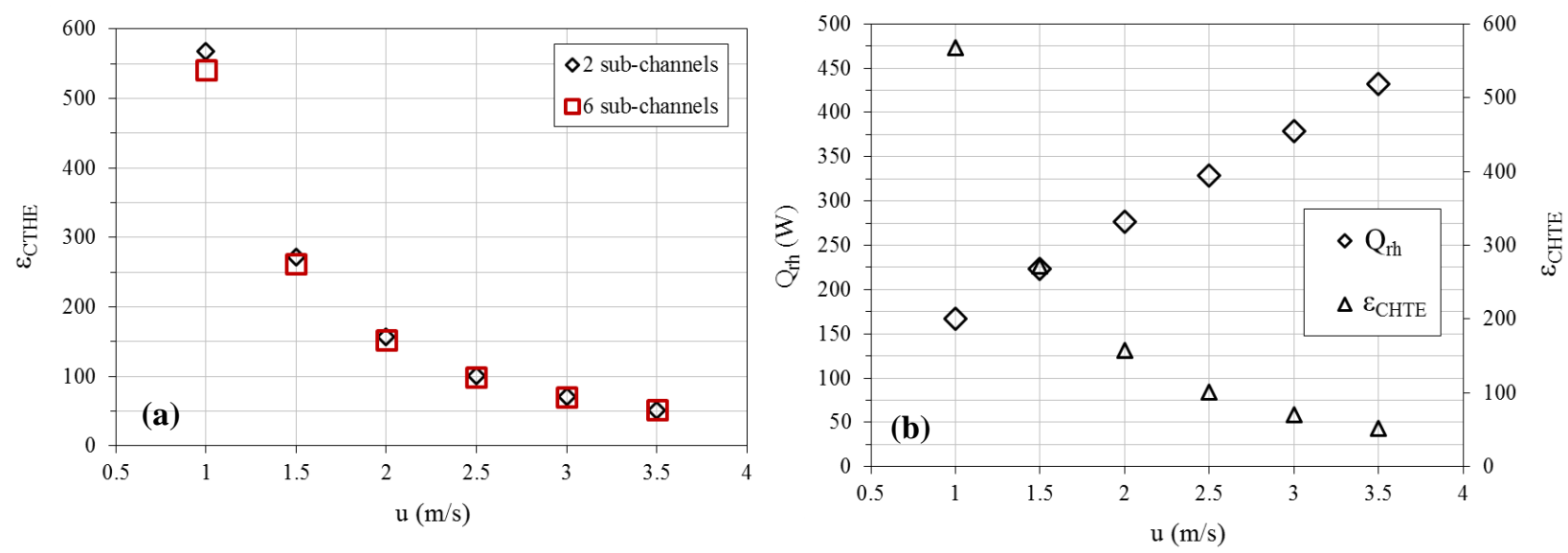

Figure 3. Changes in (a) CTHE and (b) recovered thermal power and CTHE for 2 sub-channels model depending on average air flow velocity

According to Figure 3a, there was no significant change in terms of CTHE in the average air flow velocity range investigated. The difference between the CTHE of both PHE models, especially above the average air flow velocity of $2 \mathrm{~m} / \mathrm{s}$, is $1 \%$ on average. Therefore, the 6 sub-channels PHE model, which is more favorable in terms of thermal effectiveness above the average air flow velocity of $2 \mathrm{~m} / \mathrm{s}$, has lost this advantage with regards to CTHE. Moreover, the CTHE of the 2 subchannels PHE model is $4 \%$ higher than the 6 sub-channels PHE model, below the average air flow velocity of $2 \mathrm{~m} / \mathrm{s}$. In other words, the 2 sub-channels PHE model is more preferable, both thermally and hydrodynamically, in the average air flow rate range investigated. 
In Figure $3 b$ gives change in recovered thermal power and CTHE for the 2 sub-channels PHE, depending on the average air flow velocity. The optimal average air flow velocity, both in terms of recovered thermal power and CTHE, is $1.5 \mathrm{~m} / \mathrm{s}$ for 2 sub-channels PHE.

The main objective of the study is to provide the required fresh air flow rate in a small residential building inhabited three to four people, with an average air flow velocity of $1.5 \mathrm{~m} / \mathrm{s}$, the volumetric flow rates obtained for the 2 and 6 sub-channels PHE models are $105 \mathrm{~m}^{3} / \mathrm{h}$ and $103 \mathrm{~m}^{3} / \mathrm{h}$, respectively. If it is assumed that the average fresh air requirement of one person is $20-25 \mathrm{~m}^{3} / \mathrm{h}$ in dwelling houses, the fresh air needs of 4-5 persons can be met with both PHE models. For that reason, when both PHE models are compared in terms of recovered thermal power, pressure drop, flow effectiveness, thermal effectiveness, CTHE and required fresh air flow rate, the 2 subchannels PHE model is the most suitable design. As mentioned above, the total number of fresh and stale air channels that make up the PHE has not changed since the channel heights are kept equal in the design of both PHE models. However, reducing the number of sub-channels from 6 to 2 has decreased the manufacturing costs of the support elements and the total weight of the PHE. Thus, the 2 sub-channels PHE model is also more advantageous when evaluated in terms of production cost and total weight.

By selecting 4 effective parameters with 3 levels, in Taguchi analysis applied to maximize the CTHE, the combination of the most suitable parameter levels for the PHE design can be determined from among the many possible combinations. Although the Taguchi approach helps to specify the most optimal combination, the results of Taguchi in the most appropriate combination need to be carefully examined and evaluated in detail. That is, the differences between the S/N ratios obtained for each design variable (such as the number of sub-channels) should also be examined. Even though Taguchi analysis indicates the most appropriate combination, more suitable combinations can be obtained other than the combination of parameter levels given by Taguchi in terms of factors such as production cost that are not taken into account to simplify the technical analysis. These combinations may vary according to the design problem discussed. If similar situations are encountered in different design problems, it would be useful to re-examine the outputs to be obtained with the levels corresponding to the close $\mathrm{S} / \mathrm{N}$ ratios of each design variable.

\section{Conclusions}

In this study, the effect of the number of sub-channels on the thermal and hydrodynamic performance of an air-to-air cross-flow PHE designed to be used in the balanced ventilation system of a small house has been investigated numerically. In the design of dimensional, structural and operational variables of PHE in the flow rate range of $50-200 \mathrm{~m}^{3} / \mathrm{h}$, the number of sub-channels, average air flow velocity, channel height and plate material were selected as an effective parameters based on CFD and Taguchi method.

In the Taguchi analysis, while 4 effective 3-levels parameters have been selected and the CTHE of PHE has been selected as the performance parameter. The PHE design parameters for the highest CTHE were obtained as the number of sub-channels, channel height, average air flow velocity and plate material $6,3 \mathrm{~mm}, 2 \mathrm{~m} / \mathrm{s}$ and paper, respectively. According to the average of $\mathrm{S} / \mathrm{N}$ ratios for 
the highest CTHE, the difference in performance between 2 sub-channels PHE and 6 sub-channels PHE models is less than $1 \%$ in terms of the effect of the number of sub-channels.

Table 3. Comparison of 2 and 6 sub-channels PHE models according to different performance criteria at optimal $1.5 \mathrm{~m} / \mathrm{s}$ average air flow velocity

\begin{tabular}{lcc}
\hline Performance criteria & 2 sub-channels PHE model & 6 sub-channels PHE model \\
\hline Volumetric flow rate of fresh & $\sim 105$ & $\sim 103(\mathbf{+ 1 . 9 \% )}$ \\
air, $\mathrm{m}^{3} / \mathrm{h}$ & $\sim 223$ & $\sim 221(\mathbf{+ 1 \%})$ \\
Recovered thermal power, $\mathrm{W}$ & 8.62 & $9.23(\mathbf{- 7 . 1 \%})$ \\
Pressure drop, Pa & 538 & $509(\mathbf{+ 5 . 4 \%})$ \\
Flow effectiveness & 50.55 & $51.3(\mathbf{- 1 . 5 \%})$ \\
Thermal effectiveness, \% & 272 & $262(\mathbf{+ 3 . 7 \%})$ \\
CTHE & $\sim 386$ & $\sim 610(\mathbf{+ 5 8 \%})$ \\
Total mass of PHE support & elements, gr
\end{tabular}

Note: Bold numbers indicate increase/decrease of 2 sub-channels PHE model compared to 6 sub-channels PHE model.

In this study, while the other PHE design and operating variables are kept constant, the effect of the number of sub-channels on the recovered thermal power, pressure drop, flow effectiveness, thermal effectiveness and CTHE is numerically investigated with CFD and the results are summarized below.

- There was no significant difference in thermal power between the 2 sub-channels PHE model and the 6 sub-channels PHE model in the average air flow velocity range studied (1-3.5 m/s).

- In the 6 sub-channels PHE model, on average $10 \%$ more pressure drop was obtained than the 2 sub-channels PHE model.

- The thermal effectiveness of both PHE models ranged from 42 to $57 \%$, and the thermal effectiveness of the 6 sub-channels PHE model was $4 \%$ higher on average than the 2 subchannels PHE model.

- The flow effectiveness of the 2 sub-channels PHE model is $6 \%$ higher on average than the 6 sub-channels PHE model.

- The 2 sub-channels PHE model is more advantageous in terms of thermal and hydrodynamic (combined thermal and hydrodynamic effectiveness) performances.

- Compared to recovered power and CTHE, the optimal average air flow velocities in 2 and 6 sub-channels PHE models are $1.5 \mathrm{~m} / \mathrm{s}$. Fresh air flow rates at this velocity are $105 \mathrm{~m}^{3} / \mathrm{h}$ and $103 \mathrm{~m}^{3} / \mathrm{h}$ for 2 and 6 sub-channels PHE models, respectively. 
- In comparison with the manufacturing costs and total weight of the PHEs, the 2-channels PHE model is more preferable.

The results obtained from analyzes at average air flow velocity of optimum $1.5 \mathrm{~m} / \mathrm{s}$ has been summarized in Table 3.

\section{Nomenclature}

$\begin{array}{ll}\mathrm{E} & \text { - energy }(\mathrm{kJ}) \\ \dot{\mathrm{m}} & \text { - mass flow rate }(\mathrm{kg} / \mathrm{s}) \\ \Delta \mathrm{p} & \text { - pressure drop }(\mathrm{Pa}) \\ \mathrm{c}_{\mathrm{P}} & \text { - specific heat }(\mathrm{J} / \mathrm{kg} \mathrm{K}) \\ \mathrm{CTHE} & \text { - combined thermal and hydrodynamic effectiveness } \\ \mathrm{P} & \text { - flow energy }(\mathrm{W}) \\ \mathrm{Q} & \text { - thermal power }(\mathrm{W}) \\ \mathrm{S} / \mathrm{N} & \text { - ratio of Signal to Noise } \\ \mathrm{T} & \text { - temperature }(\mathrm{K}) \\ \varepsilon & \text { - effectiveness } \\ \dot{\forall} & \text { - volume flow rate }\left(\mathrm{m}^{3} / \mathrm{h}\right)\end{array}$

$\begin{array}{ll}\text { Subscripts } \\ \mathrm{f} & \text { - flow } \\ \mathrm{fa} & \text { - fresh air } \\ \text { fan } & \text { - fan } \\ \mathrm{i} & \text { - inlet } \\ \text { max } & \text { - maximum } \\ \text { o } & \text { - outlet } \\ \text { rh } & \text { - recovered heat } \\ \text { sa } & \text { - stale air } \\ \mathrm{t} & \text { - thermal }\end{array}$

\section{References}

[1] Verhaart J. Balanced Ventilation System, Part of the problem or part of the solution? Final Report. April 23, 2010.

[2] Küçük H., Ünverdi M., Macar H. Havadan-havaya 1sı geri kazanım cihazının Taguchi yöntemi ve HAD analizleri ile tasarımı. ULIBTK'17 21. Ulusal Isı Bilimi ve Tekniği Kongresi 2017;429-437.

[3] TESTO Whitepaper. $\mathrm{CO}_{2}$ izleme ve iç hava kalitesi. 2019.

[4] Wang Y., Kuckelkorn J., Zhao FY., Spliethoff H., Lang W. A state of art of review on interactions between energy performance and indoor environment quality in Passive House buildings. Renewable and Sustainable Energy Reviews 2017;72:1303-1319.

[5] https://www.hometips.com/how-it-works/ventilation-systems-exhaust.html. Access date: September 19, 2019.

[6] https://zehnderamerica.com/what-is-balanced-ventilation/. Access date: September 25, 2019.

[7] https://www.buildingscience.com/documents/information-sheets/info-611-balancedventilation-systems. Access date: September 25, 2019.

[8] Sakulpipatsin P, Cauberg JJM, Kooi HJ, Itard LCM. Application of the exergy concept to design effecient mechanical exhaust ventilation systems. In Building Simulation 2007. Pages 363-370.

[9] Kim MK. Baldini L. Energy analysis of a decentralized ventilation system compared with centralized ventilation systems in European climates: Based on review of analyses. Energy and Buildings 2016;111:424-433. 
[10] Cuce M. Riffat S. A comprehensive review of heat recovery systems for building applications. Renewable and Sustainable Energy Reviews 2016;47:665-682.

[11] Sibalija TV., Majstorović VD. Advanced Multiresponse Process Optimization: An Intelligent and Integrated Approach. Springer, 2016.

[12] Mori T., TSAI SC. Taguchi Methods Benefits, Impacts, Mathematics, Statistics, and Applications. ASME, 2011.

[13] Montgomery DC. Design and analysis of experiments. 4th ed. New York: John Wiley; 1997.

[14] Mitra A. Fundamentals of quality control and improvement. Wiley; 2016.

[15] Phadke, MS. Quality Engineering Using Robust Design. New Jersey: Prentice Hall; 1989.

[16] Ünverdi M., Küçük H. Performance comparison of plate heat exchangers designed using Taguchi method and computational fluid dynamics. Pamukkale Univ. Müh. Bilim Dergisi 2019; 25(4):373-386.

[17] Cengel, Y. Introduction to Thermodynamics and Heat Transfer. USA: McGraw-Hill; 2007.

[18] Kucuk H., Unverdi M. Plate heat exchanger design: a case study for ventilation systems of small residences. Innovations 2019;2:60-65

[19] ANSYS/Fluent Theory Guide. Version 15, Ansys Inc., 2013.

[20] ANSYS/Fluent User's Guide. Version 15, Ansys Inc., 2013.

[21] Patankar SV. Numerical heat transfer and fluid flow. Washington, DC: Hemisphere; 1980.

[22] Winterbone DE. Turan A. Advanced Thermodynamics for Engineers. 2th ed. Oxford: Elsevier; 2015.

[23] Shah RK, Sekulic DP. Fundamentals of Heat Exchanger Design. Hoboken, New Jersey: John Wiley\&Sons;2003.

[24] White FM. Fluid Mechanics. 8th ed. New York: McGraw-Hill; 2016. 